\title{
MAKALAH BOLA VOLI
}

D

I

S

U

S

U

$\mathrm{N}$

Oleh:

Nama:Nelly Astiana Napitupulu

Kelas :X MIA -3

SMA NEGERI 3 MEDAN

Tahun ajaran 2019/2020 


\section{KATA PENGANTAR}

Puji syukur kehadirat Tuhan Yang Maha Esa atas segala rahmatNYA sehingga makalah ini dapat tersusun hingga selesai . Tidak lupa kami juga mengucapkan banyak terimakasih atas bantuan dari pihak yang telah berkontribusi dengan memberikan sumbangan baik materi maupun pikirannya.Dan harapan Saya semoga makalah ini dapat menambah pengetahuan dan pengalaman bagi para pembaca, Untuk ke depannya dapat memperbaiki bentuk maupun menambah isi makalah agar menjadi lebih baik lagi.Karena keterbatasan pengetahuan maupun 
pengalaman Saya, Saya yakin masih banyak kekurangan dalam makalah ini, Oleh karena itu Saya sangat mengharapkan saran dan kritik yang membangun dari pembaca demi kesempurnaan makalah ini.

\section{DAFTAR ISI}

Kata Pengantar

DAFTAR ISI

BAB I PENDAHULUAN
A.Latar Belakang
B. Rumusan Masalah
C.Tujuan Penulisan
D.Manfaat Penulisan

\section{BAB II PEMBAHASAN}
A. Sejarah Bola Voli
B. Pengertian Bola Voli
C. Peraturan Dalam Olahraga Bola Voli
D. Formasi Dalam Olahraga Bola Voli
E. Lamanya Permainan
F. Pelanggaran Dalam Olahraga Bola Voli
G. Sistem Pertandingan
H. Kesalahan
I. Lapangan Voli
J. Teknik Dasar Permainan Bola Voli 

A. Saran
B. Kesimpulan

\section{BAB I PENDAHULUAN}

\section{Latar Belakang.}

Pemainan bola voli merupakan pemainan beregu yang dimainkan oleh dua regu dengan jumlah pemain masing - masing regu enam orang. Dimainkan dengan cara memvoli bola hilir mudik diatas net dan masing - masing regu berusaha secepat nya menjatuhkan bola di lapangan lawan dengan pantulan bola sempurna. Penguasaan teknik, kemampuan fisik, taktik, dan mental yang baik, serta kerja sama sangat di butuhkan untuk memenangkan permainan .Permainan bola voli diciptakan oleh William G. Morgan pada tahun 1895. Beliau adalah seorang pembina pendidikan jasmani pada organisasi Young Men's Christian Association (YMCA) di kota Massachusetts, Amerika Serikat. Pada mulanya, pemainan bola voli di beri nama mintonete, di mana tujuan semula, yaitu untuk mengembangkan kesegaran jasmani pada tubuh, selain untuk bersenam umum.

Kemudian, permainan ini di ubah menjadi volleyball yang artinya memvoli bola secara bergantian. Tahun 1892, YMCA berhasil mengadakan kejuaraan nasional bola voli di Amerika Serikat. Pada tahun 1847, untuk pertama kalinya permainan bola voli dipertandingkan di Polandia. Pada tahun 1948 dibentuk organisasi bola voli dunia dengan nama IVBF (International Volley Ball Federation ) dengan beranggota 15 negara dan berpusat di Paris.

Permainan bola voli di Indonesia berkembang dengan sangat pesat di seluruh lapisan masyarakat, sehingga timbul klub - klub di kota - kota besar di seluruh Indonesia. Permainan bola voli di Indonesia sudah di kenal sejak tahun 1982 yang di bawa oleh orang - orang Belanda. Namun pada saat itu permainan ini belum populer di masyarakat. Setelah proklamasi kemerdekaan Indonesia, perkembangan bola voli nasional dan organisasi bola voli semakin cepat dan populer. Pada PON II di Jakarta tahun 1951 permainan bola voli mulai dipertandingkan, namun pada saat itu belum ada / belum terbentuk organisasi bola voli. Baru pada tanggal 22 Januari 1955 dibentuk organisasi bola voli nasional dengan nama Persatuan Bola Voli Seluruh Indonesia 
(PBVI), dengan ketua W.J.Latumenten.Sejak saat itu mulai di dakan kejuaraan bola voli nasional dan organisasi bola voli nasional juga ikut dalam kegiatan yang bertaraf internasional, seperti Sea Games, Asian Games, bahkan Olympiade. Pada tahun 1996 untuk pertama kalinya tim bola voli indonesia mengikuti pertandingan Olympiade di Atlanta, Amerika Serikat. Bahkan untuk bola voli pantai Indonesia merupakan negara yang menjadi unggulan dalam kejuaraan dunia.

\section{Rumusan Masalah}

Adanya permainan bola voli yang sering dimainkan maka menimbulkan pertanyaan diantaranya :

1. Apa peraturan dalam permainan bola voli

2. Apa teknik dasar dalam permainan bola voli

3. Apa yang dimaksud smash dan bagaimana cara melakukan smash dalam permainan bola voli

4. Apa yang dimaksud blok(bendungan) dan bagaimana cara melakukan block / bendungan

5. Bagaimana cara melakukan kombinasi teknik dasar (tekni terpadu) dalampermainan bola voli

6. Bagaimana cara melakukan teknik terpadu

\subsection{Tujuan}

Tujuan penyusunan makalah ini adalah :

1. Memenuhi salah satu tugas mata pelajaran

2. Mengetahui hal mengenai bola voli

\section{Manfaat Penulisan}

makalah ini dapat dijadikan acuan dalam melakukan olahraga Bola Voli dan mendapat pengetahuan tentang sejarah olahraga Bola Voli, pengetian olahraga Bola 
Voli, tehnik-tehnik yang digunakan dalam olahraga Bola Voli, mengatahui ukuran dan bentuk lapangan dari olahraga Bola Voli, mengetahui peraturan dalam olahraga Bola Voli dan dapat mengetahui sara dan prasarana yang digunakan dalam olahraga Bola Voli

\section{BAB II PEMBAHASAN}

\section{A. Sejarah Bola Voli}

Permainan bola voli diciptakan oleh William G. Morgan pada tahun 1895. Dia adalah seorang pembina pendidikan jasmani pada organisasi "Young Man Christian Association" (YMCA) di kota Massachussets, Amerika Serikat. Mula-mula permainan bola voli diberi nama "mintonette", dimana permainannya hampir serupa dengan permainan badminton. Jumlah permain tidak terbatas, sesuai dengan tujuan semula, yaitu untuk mengembangkan kesegaran dan kebuagaran jasmani pada buruh di samping bersenam umum.

Kemudian permainan ini diubah menjadi Volleyball yang artinya kurang lebih memvoli bola berganti-ganti. Pada tahun 1892 YMCA berhasil mengadakan kejuaraan nasional bola voli di negara Amerika Serikat. Pertandingan bola voli yang pertama tahun 1947 di Polandia. Pada tahun 1948 IVBF (International Volley Ball Federation) didirikan dengan anggota 15 negara dan berpusat di Paris. Dalam Perang Dunia II permainan ini tersebar di seluruh dunia terutama di Eropa dan Asia. Setelah Perang Dunia II prestasi dan popularitas permainan bola voli di AS menurun, sedangkan di negara lain terutama di Eropa Timur dan Asia berkembang sangat cepat dan massal. Indonesia mengenal permainan bola voli sejak tahun 1928, yaitu pada zaman penjajahan Belanda.

Permainan bola voli di Indonesia berkembang sangat pesat di seluruh lapisan masyarakat, sehingga timbul klub-klub di kota besar di seluruh Indonesia. Dengan dasar itulah, maka pada tanggal 22 Januari 1945 PBVSI (Persatuan Bola Voli Seluruh Indonesia) didirikan di Jakarta bersamaan denga kejuaraan di Yogyakarta. Setleah tahun 1962 perkembangan bola voli seperti jamur tumbuh di musim hujan.

\section{B. Pemgertian Bola Voli}

Pengertian Bola Voli adalah sebuah olahraga beregu atau tim dan setiap tim terdiri atas 6 pemain aktif dan 6 pemain dibangku cadangan. Masing-masing tim belomba 
mengumpulkan angka sebanyak-banyaknya untuk memenangkan pertandingan tersebut dengan cara menjatuhkan bola ke dalam lapangan lawan, juga bisa mendapatkan angka dengan syarat lawan melakukan kesalahan yang diselengarakan dibawah peraturan.

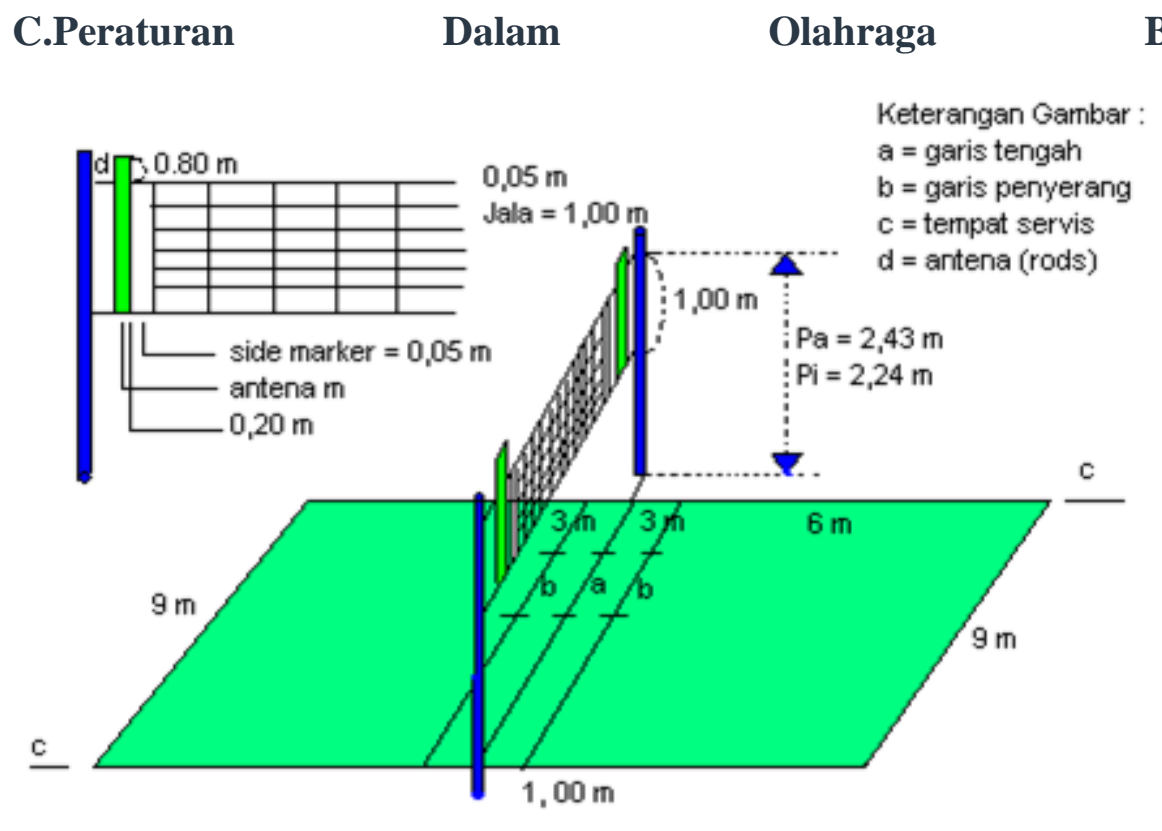

\section{Net/ Jaring}
a. Panjang
$: 9,5 \mathrm{~m}$
b. Lebar
$: 1 \mathrm{~m}$
c. Tinggi jaring putra : $2,43 \mathrm{~m}$
d. Tinggi jaring putri $\quad$ :2,24 m

Di bagian tepi jaring di pasang antena dengan ukuran panjang antena 1,80 m. 


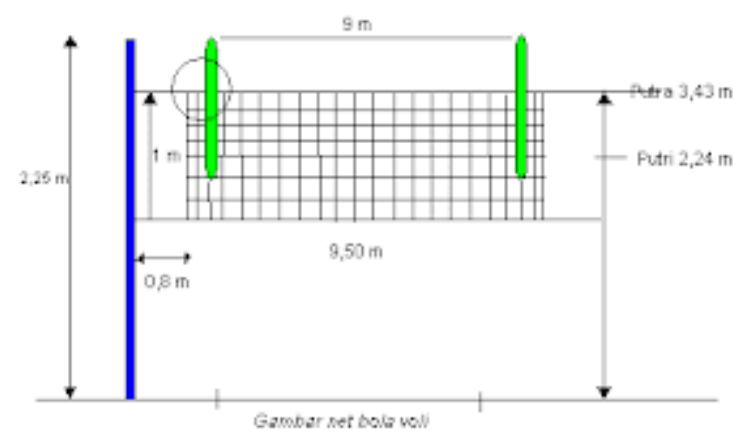

\section{Jumlah Permain}
a. Setiap regu terdiri dari 6 orang permain
b. Permainan cadangan maksimal 6 orang

\section{Pergeseran Permain}

Jika regu penerima servis berhasil mematikan bola di lapangan lawan, maka permain bergeser satu posisi searah jarum jam (misalnya : posisi satu ke posisi enam, posisi enam ke posisi lima, posisi lima ke posisi empat, dan seterusnya)

\section{Game/ Set.}

Permainan ditentukan dengan game/set. Regu yang memperoleh / mengumpulkan angka 25 terlebih dahulu adalah pemenang dalam game tersebut. Jika kedudukkan angka 24 -24, maka dinyatakan jus (deuce) dan regu yang memperoleh selisih dua angka terlebih dahulu adalah pemenangnya.

Kemenangan regu bola voli ditentukan dengan dua sistem:

a. Sistem Two Winning Set yaitu setiap regu dikatakan menang bila telah memenangkan dua set.

b. Sistem Three Winning Set yaitu regu dikatakan menanng bila memenangkan tiga set 


\section{Memainkan Bola}

a. Suatu regu berhak memukul / memainkan bola maksimal 3 kali (disamping blok)

b. Seorang permain boleh memukul / memainkan bola dua kali berturut turut (kecuali memblok / membendung)

c. Permain diperbolehkan memainkan bola menggunakan seluruh bagian tubuh (misalnya : kaki, kepala) dengan catatan pantulan bola sempurna / tidak berhenti.

d. Dua atau tiga permain boleh memukul bola pada saat yang sama (serentak)dan hal itu di hitung sebagai dua atau tiga kali pukulan (kecuali membendung)

e. Jika dua atau tiga permain menjangkau bola tetapi hanya satu permain yang memukulnya maka dihitung satu pukulan

\section{Permainan Dekat Net}

a. Seorang pembendung (bloker) boleh menyentuh bola di daerah lawan, asal tidak menggangu permain lawan (menyentuh bola sebelum dipukul lawan)

b. Setelah melakukan serangan (smash) tangan boleh melewati net / masuk ke daerah lawan

c. Boleh melewati ruang permain lawan di bawah net, asalkan tidak mengganggu permain lawan

d. Tidak noleh menyentuh / menginjak garis tengah

e. Bagian dari badan tidak boleh menyentuh lapangn lawan

\section{Bola Keluar}

Bola dinyatakan keluar apabila : 

a. Jatuh seluruhnya di sisi luar garis - garis batas lapangan
b. Menyentuh bola diluar lapangan
c. Menyentuh antena, tali, tiang atau net di luar batas antenna

\section{Kesalahan - Kesalahan Pada Saat Bermain}
a. Bola dipukul menyentuh antena /rods
b. Bola dipukul keluar lapangan
c. Bola dipukul menyentuh suatu benda di luar lapangan
d. Pemain menyentuh net
e. Pemain baris belakang melakukan smash dari depan garis serang
f. Seorang pemain memukul bola dua kali berturut - turut (kecuali memblok)
g. Pemain pengganti masuk lapangan dengan melapor

\section{Kesalahan - Kesalahan Pada Saat Servis}
a. Bola servis menyentuh antena
b. Pada saat memukul bola, kaki menginjak garis lapangan
c. Bola tidak dilambungkan terlebih dahulu
d. Bola dipukul keluar lapangan
e. Mengulur - ulurkan waktu / memperlambat permainan
f. Servis dari luar garis perpanjangan lapangan.

\subsection{Teknik Dasar Permainan Bola Voli}

\section{Servis Tennis (Tennis Servis)}




\section{a. Sikap pemulaan}

Berdiri dengan kaki kiri ke depan, bola di pegang dengan dua tangan (tangan kiri menyangga bola dan tangan kanan memengang bagian atas).

\section{b. Pelaksanaan}

Bola dilambungkan dengan tangan kiri ke atas kurang lebih meter di atas kepala. Tangan kanan segera ditarik kebelakang atas kepala , telapak tangan menghadap ke depan. Kemudian bola dipukul dengan tangan pada bagian belakang atas, dibantu dengan lecutan pergelangan tangan, sehingga jalannya bola top spin (berputar ke depan). Gerakan diakhiri dengan melangkahkan kaki ke depan

\section{Servis Mengapung(Floanting Servis)}

\section{a. Sikap permulaan}

Berdiri dengan kaki kiri ke depan, bola dipengan dengan tangan kiri, tangan kanan berada di samping atas kepala setinggi pelipis.

\section{b. Pelaksanaan}

Bola dilambungkan dengan tangan kiri tidak terlalu tinggi ke atas kanan. Begitu bola melambung ke atas setinggi kepala, bola segera di pukul dengan tangan kanan di bagian tengah belakang. Pada saat memukul bola tidak ada gerakkan/lecutan pergelangan tangan, sehingga jalannya mengapung/mengambang. Gerakkan diakhiri dengan melangkahkan kaki ke depan.

Pada servis mengapung sikap tangan dalam keadaan menggenggam atau ibu jari dilipat ke dalam menempel pada telapak tangan.

\subsection{Teknik Dasar Smash}


Smash adalah memukul bola yang dilakukan di atas net dengan kuat dan keras hingga bola jatuh menukik di lapangan lawan, dan sulit untuk dikembalikkan /diterima. Smash sendiri merupakan rangkaian gerakkan yang komplek terdiri dari empat tahap sehingga diperlukan koordinasi gerakkan yang baik untuk melakukannya. Keempat tahapan smash tersebut adalah:

\section{Langkah awalan}

Diawali dengan sikap berdiri agak serong, dengan jarak $2-4 \mathrm{~m}$ dari net. Langkahkan kaki ke depan kaki kiri diikuti dengan kaki kanan dan langkah panjang kaki kiri dengan posisi terakhir kaki hampir sejajar untuk ditekuk/ posisi badan merendah.

\section{Tolakan/ tumpuan}

Sambil merendahkan badan kedua lengan di belakang badan, segera lakukan tolakan ke atas dengan kuat sambil mengayun lengan ke depan atas, tangan kanan berada di samping atas kepala.

\section{Perkenalan bola}

Perkenalan/pukulan bola dilakukan saat mencapai titik tertinggi dari loncatan, jarak bola satu jangkauan tangan, posisi bola tepat di depan atas kepala. Lakukan pukulan di bagian atas belakang bola dengan telapak tangan terbuka disertai dengan lecutan tangan hingga menghasilkan bola top spin.

\section{Pendaratan.}

Pendaratan dengan kedua kaki sejajar disertai gerakan ngeper pada kedua lutut, dan tetep menjaga keseimbangan untuk segera kembali pada sikap siap normal.

\subsection{Teknik Dasar Memblok (Membendung)}


Merupakan salah satu teknik bertahan yang dilakukan di atas net, dengan cara melompat sambil menjulurkan kedua tangan untuk menahan smash lawan.

Ada dua teknik blok yaitu

\section{Block aktif}

Di mana saat melakukan block kedua tangan dengan kuat menahan bola dan saat perkenaan tangan tangan aktif menekan bola ke bawah.

\section{Block pasif}

Dimana saat melakukan tangan dijulurkan kdekat net tanpa disertai gerakkan apapun. Cara ini dilakukan oleh pemain dengan postur tubuh pendek dengan keterbatasan jangkauan tangan.

Block yang baik sangat efektif untuk melakukan pertahanan smash lawan kkarena dapat dilakukan secara perorangan maupun berpasangan dua atau tiga pemain sekaligus.

Teknik melakukan block / bendungan.

\section{Sikap awal}

Berdiri menghadap net kaki sejajar kedua tangan di depan dada, lutut ditekuk badan agak condong ke depan. Pandangan fokus ke arah bola dan pergerakkan smasher lawan.

\section{Pelaksanaan}

Lakukan tolakan dengan kuat kedua tangan dijulurkan ke atas net selebar bahu telapak jari-jari terbuka. Arahkan tangan ke daerah perkiraan lintasan bola/smash lawan. Saat perkenaan jari - jari ditegangkan agar kuat menahan smash lawan. 


\section{Gerakan akhir}

Lakukan pendaratan dengan kedua kaki disertai gerakan ngeper pada lutut, seimbangan tetap terjaga dan segera mengambil posisi siap kembali pada permainan.

\subsection{Kombinasi Teknik Dasar(Teknik Terpadu)}

Teknik terpadu atau latihan kombinasi merupakan bentuk latihan dengan mengkombinasikan beberapa unsur teknik dasar permainan voli yang ada.

Contohnya:

\section{Latihan Kombinasi Passing Atas Dan Passing Bawah}

Cara melakukannya :

a. Lakukan passing atas tegak lurus setelah bola turun lakukan pula passing bawah dan setelah bola naik/ melambung ke atas dan seterusnya.

b. Untuk tahap pertama dilakukan di tempat dan tahap kedua lakukan sambil berjalan.

\section{Latihan Kombinasi Servis, Smash, Dan Passing Bawah}

Cara melakukannya:

a. Pemainan 1 melakukan servis atas/smash

b. Pemain 2 melakukan passing bawah kea rah pemain 3

c. Pemain 3 menangkap bola dan meneruskannya pada pemain 4 dengan digulirkan

d. Setiap pemain setelah menyentuh bola langsung bergerak lari berpindah tempat 


\subsection{Posisi Pemain}

Posisi pemain bola voli dibagimenjadi dua kelompok yaitu :

1. Pemain posisi depan 3 orang yaitu posisi 2,3 , dan 4

2. Pemain posisi belakang 3 orang yaitu posisi 1,6 , dan 5

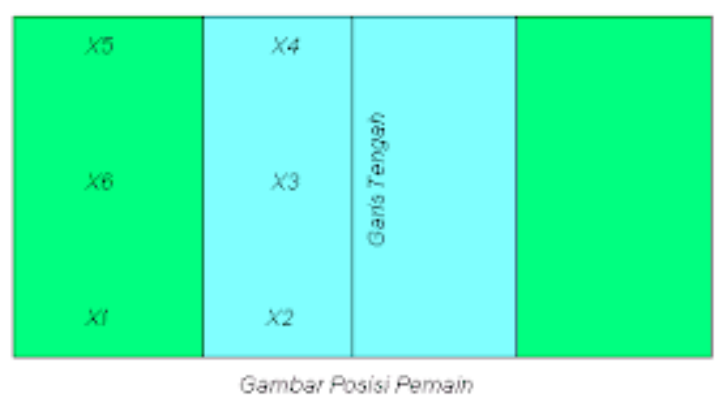

Posisi 2, 3, dan 4 bertugas sebagai penyerang sekaligus pertahanan di daerah atas net (blok). Posisi 5, 6, dan 1 bertugas sebagai pertahanan di daerah belakang dan tidak boleh melakukan blok maupun serangan dari daerah depan. Posisi 1 melakukan servis pada awal permainan.

\section{Formasi Dalam Olahraga Bola Voli}

Dalam olahraga Bola Voli terdiri dari 6 pemain dan 6 pemain tersebut mempunyai peran masing-masing sebagai berikut:

Pemain yang bertugas sebagai Tosser

Pemain yang bertugas sebagai Spiker

Pemain yang bertugas sebagai Libero

4

Pemain yang bertugas sebagai Blocker

Berikut penjelasanya

Tosser adalah pemain yang bertugas mengatur jalanya pertandingan atau mengumpankan Bola ke teman-temanya untuk dismash ke lawan. Dalam olahraga Bola 
Voli Tosser menerima Bola ke-2

lalu diumpankan ke temannya. Untuk Bola yang pertama diterima oleh teman lainya lalu diumpan ke Tosser.

Spiker adalah pemain yang bertugas memukul Bola dengan keras supaya Bola masuk ke daerah lawan atau juga bisa Bola mengenai lawan lalu out.

3 Libero adalah pemain yang bertugas menerima Bola dari serangan lawan, atau juga bisa disebut pemain bertahan. Libero adalah salah satu pemain yang mempunyai passing bagus untuk mengamankan Bola, pemain Libero tidak boleh maju untuk melakukan smash.

4 Blocker/defender adalah pemain yang bertugas untuk membendung serangan lawan dengan cara memblock Bola agar Bola tidak masuk kedaerah kita.

\section{E. Lamanya Permainan}

Seriap tim harus mengumpulkan 25 angka untuk memenangkan pertandingan dalam 1 set. Dalam permainan Bola Voli setiap pertandingan terdiri dari 3 set atau juga 5 set.

Twi winning set, yaitu salah satu tum memenagkan pertandingan deua set kemenangan.

Three winning set, yaitu salah satu tim memenangkan pertandingan tiga set kemenangan Best of five berlangsung lima set.

\section{F. Pelanggaran Dalam Olahraga Bola Voli}

Jenis pelanggaran dalam olahraga Bola Voli

1 Mempengaruhi wasit atau mempengaruhi wasit.

2 Berbicara tidak sopan kepada tim lawan dan wasit.

3 Bermain tidak sportif.

4 Sering menegur wasit.

5 Meninggalkan lapangan begitu saja saat pertandingan tanpa seizin wasit. 


\section{G. Sistem Pertandingan}

Sistem pertandingan dalam olahraga Bola Voli

1 menggunakan sistem setengah kompetisi yang terdiri dari 8 tim dan akan dibagi ke dalam 2 grup, masing-masing grup terdiri 4 tim.

2 Setiap tim terdiri dari 12 pemain meliputi 6 pemain inti dan 6 pemain cadangan.

3 Pergantian pemain dalam olahraga Bola Voli tidak dibatasi saat berlangsungnya permainan

4 Jumlah pemain minimum yang boleh bermain di lapangan adalah sebanyak 6 orang. Apabila di lapangan terdapat kurang dari 6 orang, maka tim yang bersangkutan dianggap kalah.

$5 \quad$ Setiap pertandingan berlangsung tiga babak (best of three)

6 Setiap pertandingan berlangsung lima babak/final (best of five).

7 Sistem hitungan yang digunakan adalah 25 rally point. Bila angka kedua tim seri (24-24) maka pertandingan ditambah 2 poin. Tim yang pertama kali unggul dengan selisih 2 poin akan memenangkan pertandingan.

8 Tidak boleh melempar ataupun menagkap bola. Bola voli harus dipantulkan. Seluruh bagian tubuh legal untuk memantulkan bola kecuali dengan cara menendang.

9 Setiap satu pemain tidak boleh melakukan double (dua kali mengenai bola) dan jumlah maksimal pukulan 3 kali di daerah sendiri kemudian diseberangkan ke daerah lawan.

10 Bola yang keluar dari lapangan belum dihitung sebagai out sebelum menyentuh permukan tanah.

11 Time out dilakukan hanya sekali dalam setiap babak dan berlangsung hanya dalam semenit

\section{H. Kesalahan Yang Merugikan Tim}

Meliputi: 
1 Dengan sengaja salah satu pemain menyentuh net atau juga salah satu pemain melewati batas garis tengah lapangan lawan.

2 Pemain tidak boleh menangkap Bola ataupun melempar, pemain harus memantulkan Bola tanpa mengenai dasar lapangan.

3 Bola yang keluar dari lapangan belum dinyatakan out apabila belum menyentuh permukaan lapangan.

4 Pada saat melakukan service Bola melewati lapangan atau keluar dari lapangan maka poin bago lawan, bagitu juga sebaliknya penerima service lawan yang membuat Bola keluar dari lapangan maka lawan mendapatkan poin

$5 \quad$ Pada saat melakukan service seluruh pemain harus berda didalam lapangan

6 Pemain melakukan spike diatas lapangan lawan

7 Semua bagian tubuh boleh untuk memantulkan Bola namun tidak boleh cara ditendang

8 Pemain lawan menyentuh net 2 kali saat berlangsungnya permainan maka Bola dihitung sebagai double foults.

\section{Lapangan Bola Voli}

ukuran lapangan bola voli berbentuk persegi panjang. Dibelah oleh garis tengah menjadi dua bagian yang berukuran sama. Panjang lapangan 18 meter, sedengkan lebarnya 9 meter.

Dalam setiap bagian lapangan terdapat garis serang, tempat spiker melakukan smash dan juga blocker malakukan blok. Garis serang memiliki ukuran 3 meter. Dibelakang lapangan terdapat area servis untuk memulai parmainan voli. Sejajar dengan garis tengah yang membelah lapangan, direntangkan net yang membatasi area permainan. Untuk net lapangan bola voli terdapat dua macam ketinggian, yakni untuk putra 2.43 meter dan untuk putri 2.24 meter. Lebar jaring net sebesar 1 meter. 


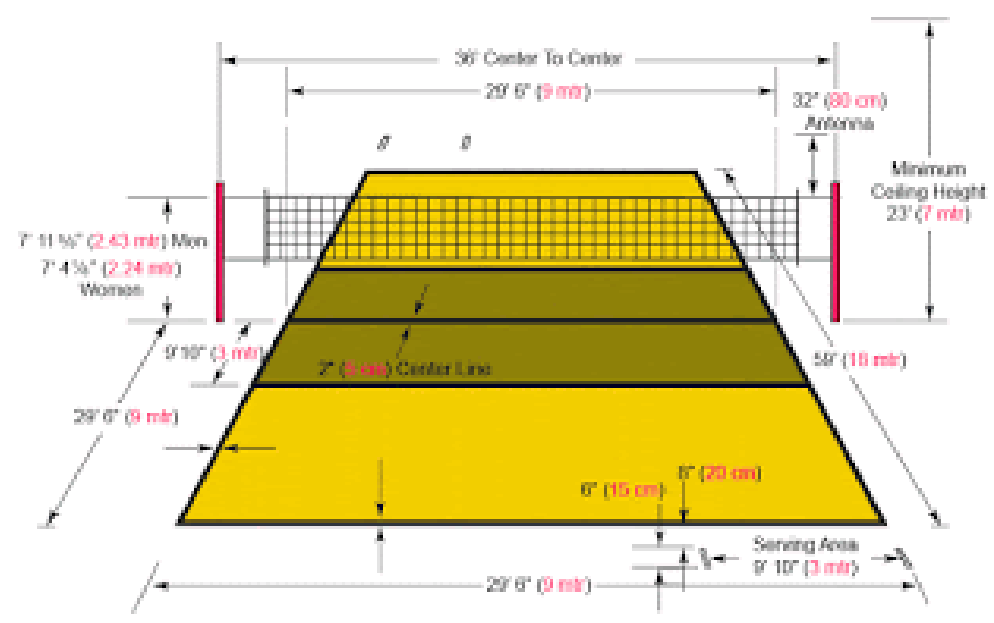

\section{J. Teknik Dasar Permainan Bola Voli}

1 Service

Bola dilambungkan dengan tangan kiri ke atas kurang lebih meter di atas kepala. Tangan kanan segera ditarik kebelakang atas kepala, telapak tangan menghadap ke depan. Kemudian bola dipukul dengan tangan pada bagian belakang atas, dibantu dengan lecutan pergelangan tangan, sehingga jalannya bola top spin (berputar ke depan). Gerakan diakhiri dengan melangkahkan kaki ke depan.

2 Smash

Diawali dengan sikap berdiri agak serong, dengan jarak $2-4 \mathrm{~m}$ dari net. Langkahkan kaki ke depan kaki kiri diikuti dengan kaki kanan dan langkah panjang kaki kiri dengan posisi terakhir kaki hampir sejajar untuk ditekuk/ posisi badan merendah.

$3 \quad$ Memblok (membendung)

Merupakan salah satu teknik bertahan yang dilakukan di atas net, dengan cara melompat sambil menjulurkan kedua tangan untuk menahan smash lawan.

Lakukan passing atas tegak lurus setelah bola turun lakukan pula passing bawah dan setelah bola naik/ melambung ke atas dan seterusnya.

Untuk tahap pertama dilakukan di tempat dan tahap kedua lakukan sambil berjalan. 


\section{BAB III PENUTUP}

\section{A. Kesimpulan}

Dari beberapa uraian penjelasan yang telah dikemukakan maka penulis dapat menyimpulkan bahwa dengan pendidikan jasmani, olahraga dan kesehatan ini khususnya dalam olahraga Bola Voli, maka dapat mengetahui tentang sejarah Bola Voli, pengertian Bola Voli, teknik teknik dasar Bola Voli dll

\section{B. Saran}

bahwasanya untuk dapat melakukukan gerakan yang baik dan benar dalam olahraga Bola Voli, kita harus mengenal teknik-teknik dasar dalam melakukan Bola Voli itu sendiri dan tidak lupa melakukan latihan untuk mempermantap gerakan kita. 